\title{
Editorial
}

\section{Electronic imaging and the visual arts}

This issue contains a number of papers which were read at a conference "Electronic Imaging and the Visual Arts" (EVA) held at the National Gallery, London, in July 1993.

Many aspects of this subject were covered at the meeting including descriptions of systems in use, existing and proposed telecommunications, and the acquisition, storage, display, and publication of images. The images often form parts of a multimedia system. Such systems are now becoming quite widely used in arts galleries and museums. They may be interactive in order to encourage the participation of visitors who are otherwise passive observers. Multimedia is often labeled "a technique looking for an application" - a label which is no longer applicable in the arts field. Four of the projects described in the papers are supported by CEC ESPRIT, RACE, or IMPACT funding.

The variety of projects described illustrates the current range of electronic imaging activities. Three papers are about multimedia projects in museums. There are also three papers covering the subject of the inter-communication of imaging data. Other papers cover conservation, high-quality colour reproduction of pictures, historical applications, copyright and indexing. The Apple Macintosh microcomputer is often used - it comes across as the dominant platform. Kodak Photo-CD receives a mention as a very promising newcomer.

The articles about telecommunications are to do with the Remote Access to Museum Archives (RAMA) telecom system to be used for inter-museum access to databases. The telecommunication links remain a problem, an FDDI network being mentioned for communication between French museums, with ISDN/X25 for inter-country telecom links.

The papers can speak for themselves but there are several features of general/interest. Jeremy Rees points out that although CEC funding is very welcome, the tackling of projects jointly by several institutions, encouraged by the CEC, adds to costs and complexity. Rees also says that funding under IMPACT is "very modest". He continues: "one of the biggest problems facing any serious interactive multimedia project is one of distribution. As yet there is not a well developed means of point of sale access to such resources". He asks whether people will be 
prepared to spend at least $£ 100$, site unseen, on a CD-ROM or CD-I purchased at a bookshop or electrical shop.

Keates and Cornish raise the problems of access and protection in terms of copyright. "The intellectual property industry cannot afford to allow its products to be copied, packaged, pirated or distributed without insuring adequate economic compensation", they say. They propose a system called CITED to list and standardise a number of aspects and to deal with the relationship established by the actions taken by people such as owners, distributors, and end-users.

As at a similar conference which took place in the previous year - EVA '92 little is said in any of the papers about indexing problems. I attempted to rectify this omission with a short paper about some of the requirements. I could only find mention of it in one other paper - by Lewis and Draycott describing the preparation of 56,000 pictures included in the Wellcome Institute's history of medicine project. A "cataloging" operation is included in the flowpath diagram provided, but that is the sum total of the comments about indexing. 